\title{
Determinants of Access to Health Care Among Women in East African Countries: A Multilevel Analysis of Recent Demographic and Health Surveys from 2008 to 2017
}

This article was published in the following Dove Press journal:

Risk Management and Healthcare Policy

\author{
Amare Minyihun (1D) \\ Zemenu Tadesse Tessema $\mathbb{D}^{2}$ \\ 'Department of Health Systems and \\ Policy, Institute of Public Health, College \\ of Medicine and Health Sciences, \\ University of Gondar, Gondar, Ethiopia; \\ ${ }^{2}$ Department of Epidemiology and \\ Biostatistics, Institute of Public Health, \\ College of Medicine and Health Sciences, \\ University of Gondar, Gondar, Ethiopia
}

Background: Access to essential health care is one of the major factors associated with maternal mortality. In developing countries, improving women's access to health care has significantly reduced maternal death. Therefore, this study aimed to identify the determinants of access to health care among women in East African countries based on 2008 to 2017 Demographic and Health Surveys (DHSs).

Methods: This study used secondary data from 2008 to 2017 DHSs of 12 East African countries. A two-level mixed-effects logistic regression analysis was employed to determine the variables associated with women's access to maternal health care. The adjusted odds ratios (AORs), 95\% CI, and $\mathrm{P}$-value were computed. Variables with $\mathrm{P}<0.05$ were considered as determinants of access to maternal health care.

Results: A total of 148,483 study participants were included in this study. Women who accessed health care were $64,218(42.91 \%)$ in the region. The study revealed that access to women's health care was positively associated with factors; being educated women, having an educated husband, being from households with middle and richest wealth status, and living in different countries compared to Comoros. The study also revealed that living in a rural setting and having unplanned pregnancy were barriers to access to health care.

Conclusion and Recommendation: Women in East Africa countries have poor access to maternal health care. Residence, maternal education, husband education, income, and planned pregnancy were the predictors of access to health care. Therefore, there should be a common strategy to enhance the accessibility of health service utilization among women in the region and financial support for the poor that enables women to use health services. For better health care access, increasing the awareness of women and their partners about the significance of utilization of healthcare service focusing on uneducated persons are crucial activities.

Keywords: access, determinants, health care, women, East Africa

\section{Introduction}

One of the basic indicators of better health of the population is better socioeconomic development and improved social wellbeing. Low-income countries face different access barriers to health care. Women require more health care needs throughout their reproductive years, regardless of whether they have children. They require substantially more contact with medical providers than men of their age. Health service inequality for women is a very critical challenge in low-income
Correspondence: Amare Minyihun University of Gondar, P.o. Box: 196, Gondar, Ethiopia

Email amarebdr@gmail.com
Risk Management and Healthcare Policy 2020:13 1803-1813

1803 
countries, which affects the overall societal wellbeing. This service inequality on mothers is very common in those low-income countries which have a weak health care system. $^{1,2}$

Health service-related inequality is more dominant among women because women almost in all communities may have less land, wealth, and property while they have higher burdens of labor in the economic activities that ensure the survival, reproduction, and safety of people. In most cases, girls are less fed and educated, and physically more restricted in certain contexts. Women are also typically employed and segregated in lower-paid, less secure, and informal occupations. These all can contribute to the low level of women's access to the maternal health care. $^{3-5}$

Globally, 536,000 mothers die every year due to conception and conception-related causes. ${ }^{6,7}$ Among these numbers, 99\% $(302,000)$ of the world maternal deaths in 2015 occurred in developing regions, with sub-Saharan Africa (SSA) alone represent 66\% (201,000), followed by Southern Asia $(66,000)$. Most of these maternal deaths could be maintained through better access to quality medical care at the time of pregnancy, labor, and the postnatal period. ${ }^{8,9}$ The pattern in developing countries has shown an increasing trend, as studies from different countries of SSA, revealed maternal mortality has kept on being high as well as has been expanding after the dispatch of the women's health care initiatives. This impediment is more noteworthy in the SSA region, where a huge extent of deliveries are not assisted by skilled personnel. ${ }^{10,11}$

In East Africa, the proportion of mothers who get skilled birth attendants was below $50 \%$ and the maternal health indicators performance in these regions remains low. Maternal mortality and morbidity can be reduced by accessing and utilizing basic health care services. However, in SSA, women are not utilizing basic health services as per the required level. This leads to low coverage of maternal health services. Lack of using the essential continuum of care by mothers affects the health status and life of mothers and babies. ${ }^{12}$

Likewise, the absence of access to proper obstetric care, particularly in labor, exacerbates the danger of maternal and child consequences such as death or disability. This service inequality makes mothers live to have a poor maternal outcome. The probability of dying for those mothers in East Africa is 1 in 31, as compared to 1 in 4300 in a high-income country. ${ }^{13}$ To decrease the danger of maternal and baby suffering and mortality, particularly in places where the general financial status is low, access and usage of obstetric care is the best way. The best modality to overcome the maternal health problem is enhancing the maternal service program among the beneficiaries. $^{14}$

Achieving universal healthcare coverage including financial risk protection for all, and $\mathrm{r}$ a key objective (target 3.8) of the United Nations' Sustainable Development Goals (SDG) ensure healthy lives and promote well-being for all. Health systems of the region face the challenge of growing populations and increasing demand. The challenge can also result from nondemographic factors such as the emergence of new (often expensive) treatments. In some East African countries, costs and waiting time remain important barriers to accessing healthcare. Besides, the increasing demand for healthcare resources and public budgets which are often under pressure, and ensuring universal coverage and timely access to high-quality healthcare with the sustainability of health systems are challenges that require sustained government commitment. ${ }^{15-17}$

According to a European Commission (2014) Communication, access to healthcare dimensions include population coverage, affordability of healthcare (costsharing), and the basket of care; and availability of healthcare (distance, waiting times). These dimensions are interlinked. However, according to the DHS statics guide, access to health care for the reproductive women group is measured by asking multiple questions whether they have serious problems in accessing health care for themselves when they are sick, ie financial problem, permission to go for treatment, distance to the health facility, and able to go alone. ${ }^{18,19}$

Different global and regional initiatives have been adapted to enhance the health status of mothers including Millennium Development Goals (MDGs) and Sustainable Development Goals (SDGs). Even if tremendous efforts have been globally as well as locally, the health status of mothers has not still improved as expected. Evidences show that socio-economic and health-related factors are responsible for poor maternal health status and outcomes in the region. ${ }^{20-23}$ However, very few findings have analyzed how these variables impact access to maternal health services in East Africa.

Henceforth, the present study will give insight into what factors are responsible for the poor access and maternal health services, and help design interventions to address the issue of poor maternal health status and outcome. Therefore, the main objective of this study was to 
identify the determinants of access to health care among women in East African countries using the 2008 to 2017 DHSs.

\section{Methods}

\section{Study Design, Period and Setting}

This was an analysis of secondary data from DHSs of 12 East African countries conducted between 2008 and 2017. These countries are Tanzania, Burundi, Comoros, Ethiopia, Madagascar, Uganda, Kenya, Malawi, Rwanda, Zambia, Mozambique, and Zimbabwe (Figure 1)

\section{Data Source, Tool, and Sampling Procedures}

The most recent standardized DHS data of the 12 East African Countries, with at least one survey from 2008 to 2017, were included in this study. The DHS program embraces normalized strategies including uniform surveys, manuals, and field methodology to assemble the data that is practically identical across nations on the world. The DHSs are countrywide illustrative household studies that provide information from a varied scope of checking and effect assessment of indicators in the area of population, health service, and diet. The DHS data were collected using face to face interviews of women age 15-49. The surveys employed a mix of sampling procedures such as random sampling, multi-stage, and stratified sampling. The data were obtained from eligible mothers aged 15-49 years in each country. Detailed survey procedures and sampling techniques were used in collecting the information. ${ }^{24}$

\section{Sample Size}

A total of 148,483 women participated in the study which included women fom Burundi $(13,610)$, Ethiopia $(11,022)$, Kenya $(19,563)$, Comoros (2880), Madagascar $(12,407)$, Malawi (17,395), Mozambique (11,477), Tanzania (8002), Rwanda (10,051), Uganda (15,270), Zambia (13,383), and Zimbabwe (6418).

\section{Variables \\ Outcome Variable}

The outcome variable of the study was women's access to health care. Most studies have identified the travel time

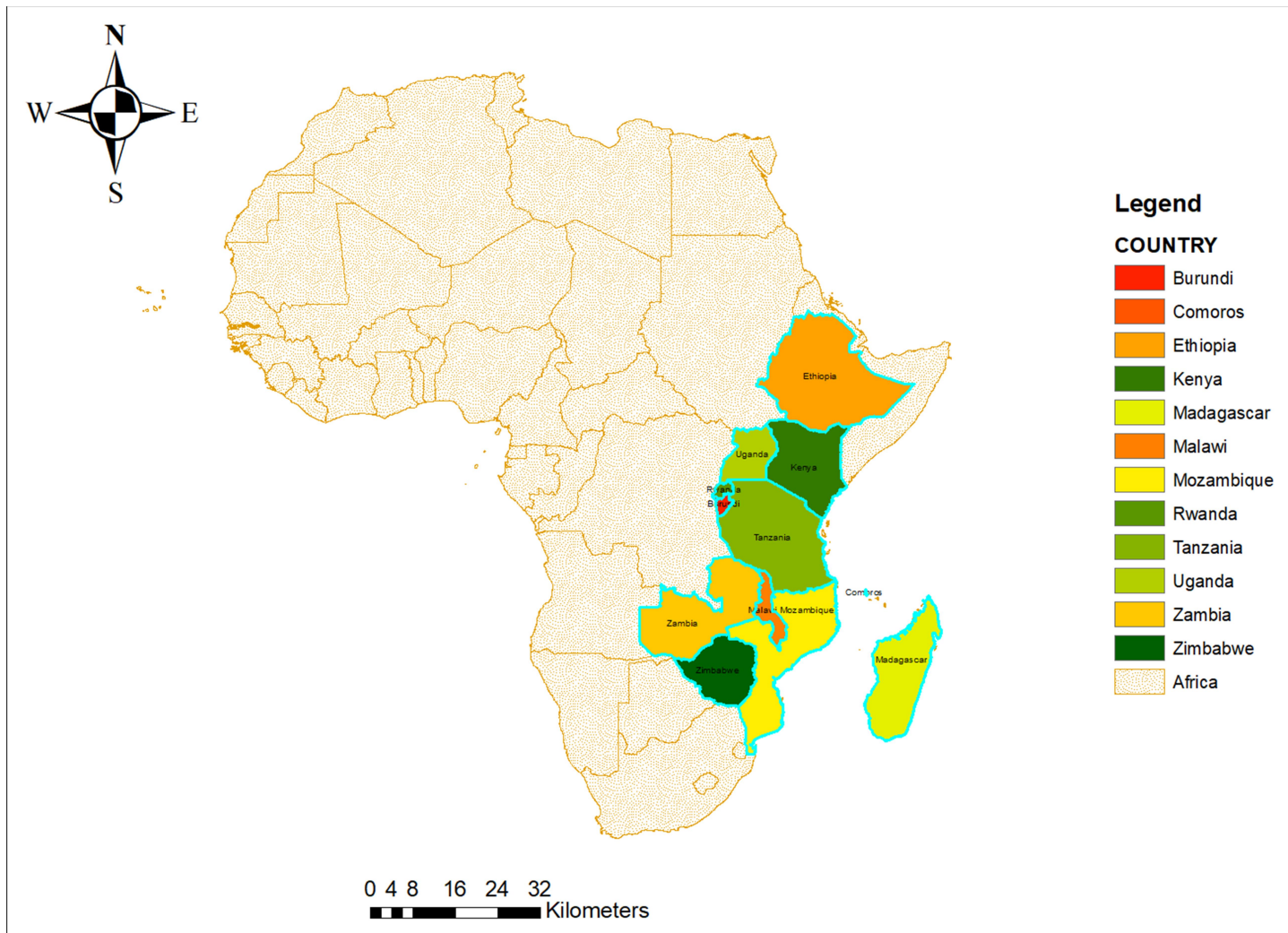

Figure I Map of Africa and Eastern African Regions to study access to health care in East Africa Region, 2020. 
and transport cost as the factors that determine access to health facilities. In the survey, women were interviewed whether a range of elements would be a major issue for them in getting to health care access. We generated a composite outcome variable using each country's DHS standard questions. ${ }^{24}$ The questions included: getting cash required for treatment; distance to the nearby health care facility; having transport accessibility; and being accompanied by others while visiting a health facility. The responses for the questions were categorized as "big problem" and "not a big problem" and the response "big problem" was coded as "0", and the response "not a big problem" was coded as " 1 ". If women reported at least one or more problems out of these problems, the women were considered to have a big problem in accessing health care facilities and coded as " 0 ".

\section{Independent Variables}

In this study, two types of variables were included: level one and level two variables. Level one variables included a residence, age group, maternal education, partner education, marital status, wealth index, maternal occupation, literacy and wanted pregnancy whereas level two variables were countries (Tanzania, Burundi, Comoros, Ethiopia, Madagascar, Uganda, Kenya, Malawi, Rwanda, Zambia, Mozambique, and Zimbabwe).

\section{Multi-Level Analysis}

Since the outcome variable was binary, multilevel multivariable logistic regression analysis was employed. Sampling weight was applied as part of a complex survey design using primary sampling unit, strata, and women's individual weight (V005). The individual and countrylevel variables related to accessing health care were checked independently in the bivariable multilevel logistic regression model and variables that were statistically significant at p-value 0.2 in the bivariable multilevel mixedeffects logistic regression analysis were considered for the individual and country-level model adjustments.

\section{Data Management and Analysis}

We pooled the data from the 12 East African countries together after extracting the variables based on literature. ${ }^{24}$ Before any statistical analysis, the data were weighted using sampling weight, primary sampling unit, and strata to restore the representativeness of the survey and take sampling design while calculating standard errors and reliable estimates. Cross tabulations and summary statistics were done using STATA version 14 software. The pooled prevalence of accessing health care with the 95\% Confidence Interval (CI) was reported for East Africa countries from 2008 to 2017.

\section{Parameter Estimation Method}

\section{Statistical Modeling}

For the determinant factors, the DHS data had a hierarchical structure. This violates the independence of observations and equal variance assumption of the traditional logistic regression model. Subsequently, women were nested inside a cluster and we assumed that women inside a similar cluster might be more like each other than women in the other country. This implies that there is a need to take into account the between cluster variability by using advanced models. Four models were fitted to identify determinants of access to healthcare. These were the null model (model without the explanatory variables), model I (model that includes individual-level variables), model II (the model that includes community-level variables), and Model III (the model that includes both individual and community-level variables). Log-likelihood ratio (LLR) and deviance test statistics were computed to examine the best fit model. The relevance of including random parameter estimates was examined using tau-squared, intra class correlation (ICC), ${ }^{25}$ proportional change in variances (PCV), ${ }^{25}$ and median odds ratio (MOR). ${ }^{26}$

Variables with $\mathrm{p}$-value $<0.2$ in the bi-variable analysis were considered in the multilevel multivariable logistic regression model. Adjusted odds ratios (AOR) with a 95\% Confidence Interval (CI) and p-value $\leq 0.05$ in model III (individual and community variables included) were used to declare significant factors associated with women's access to health care in the East Africa countries.

\section{Results}

A total of 148,483 study participants were involved in this study from the 12 East African Countries. The coverage of women's access to health care from 2008 to 2017 was $42.91 \%$ (95\% CI: 42.65\%, 43.17\%). The lowest health care access was observed in Comoros (21.53\%) and the highest was in Kenya (75.79\%). The highest number of study participants was from Kenya $(19,563$, ie $13.83 \%)$ and the smallest number of study participants was from Comoros (2880, ie $2.04 \%$ ). The study participants' median age was 28 years with an interquartile range of 24 to 34 . The study revealed that $10,471 \quad(78.08 \%)$ study 
participants were rural residents, 67,107 (47.85\%) were under the age group of 20-34 years, 100,261 (70.86) were married, $75,945(53.36 \%)$ had primary level education, and only 36,830 (28.08\%) of women had occupation (Table 1, Figures 2 and 3).

\section{Determinants of Accessing Health Care}

The empty model showed that there was a significant variation in the likelihood of accessing health care within the East African countries $\left(\sigma^{2}=5.73, p<0.001\right)$. The ICC in the empty model implied that $99 \%$ of the total variation in accessing health care was contributed to the difference between countries. The MOR was 2.44 (95\% CI: 2.13, 3.12) which implied that the odds of assessing health care were 2.44 times more likely if women were moved from low to high-risk countries. In model III (full model), the country-level variance in the study remained significant $\left(\sigma^{2}=4.25, p<0.001\right)$ adjusted for individual and country-level factors. A total of $13 \%$ variability of accessing health care that could be contributed to the country-level factors were significant. The proportional change in variance (PCV) in this study was $75 \%$ which indicated $75 \%$ of the country variance observed in the empty model was explained by both country- and individual-level variable (Table 2)

\section{Fixed Effects Analysis Result}

The study indicated that residence, maternal education, husband education, literacy, maternal occupation, wealth index, wanted pregnancy, and country were statistically significant factors women's access to health care.

The odds of accessing health care among rural residents were decreased by $43 \%$ compared to urban residents $(\mathrm{AOR}=0.57 ; 95 \% \mathrm{CI}: 0.56,0.60)$. The likelihood of accessing health care among women who had primary, secondary and higher education level was increased by $6 \%(\mathrm{AOR}=1.06 ; 95 \% \mathrm{CI}: 1.01,1.10), 22 \%(\mathrm{AOR}=$ 1.22; 95\% CI:1.15,1.29), and 84\% (AOR: 1.84; 95\%: $1.66,2.05)$, compared to illiterate women, respectively. The odds of accessing health care for women who had partners who had primary, secondary and higher education level was increased by $8 \%(\mathrm{AOR}=1.08 ; 95 \% \mathrm{CI}$ : $1.05,1.12$ ), 20\% (AOR: 1.20 ; 95\% CI: $1.20,1.31$ ), and $66 \%(\mathrm{AOR}=1.66 ; 95 \% \mathrm{CI}: 1.54,1.79)$ compared to partners who had no education, respectively. The odds of accessing health care among literates were increased by $12 \%(\mathrm{AOR}=0.12 ; 95 \% \mathrm{CI}: 1.08,1.16)$ compared to
Table I Individual and Country-Level Characteristics of Accessing Health Care in East Africa Countries Recent Demographic and Health Surveys from 2008 to 2017

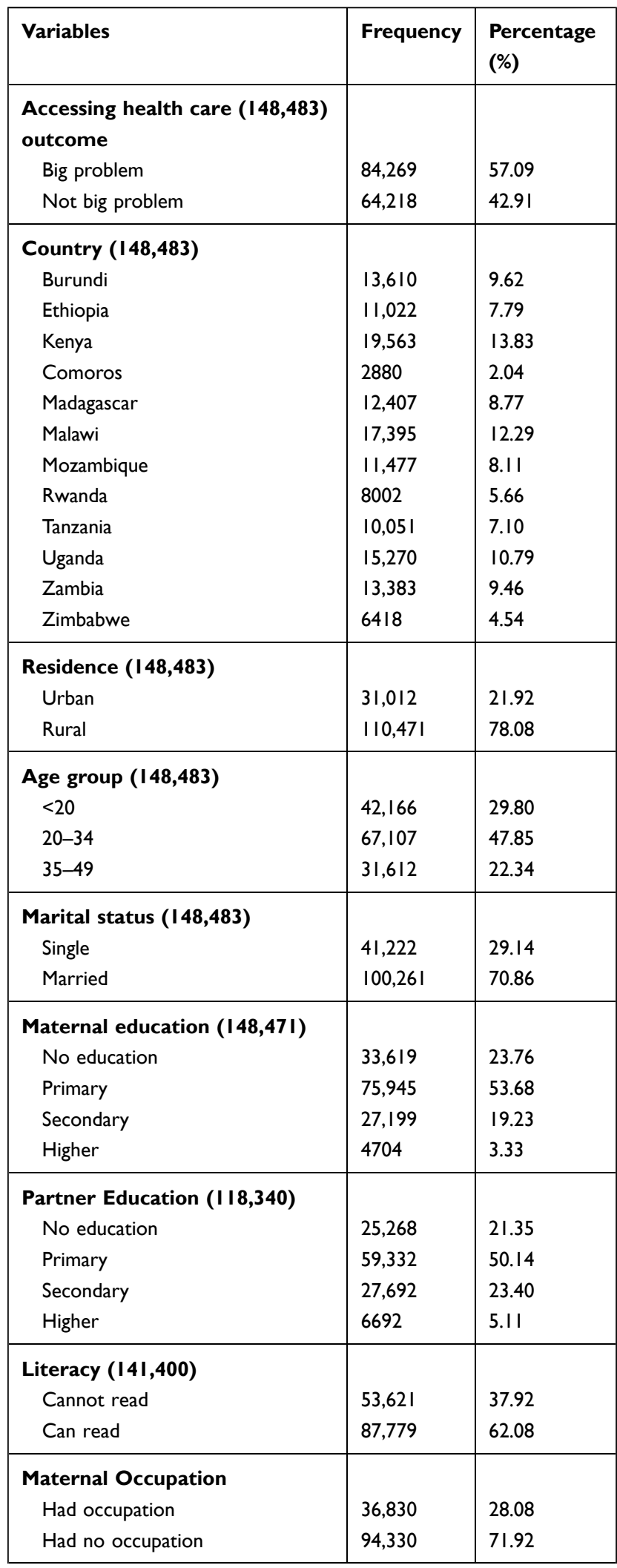

(Continued) 
Table I (Continued).

\begin{tabular}{|l|l|l|}
\hline Variables & Frequency & $\begin{array}{l}\text { Percentage } \\
\text { (\%) }\end{array}$ \\
\hline $\begin{array}{l}\text { Wealth Index } \\
\text { Poor }\end{array}$ & 64,367 & 45.49 \\
Middle & 27,586 & 19.50 \\
Rich & 49,528 & 35.01 \\
\hline Pregnancy wanted (13 ,2 I5) & & \\
Yes & 121,189 & 92.36 \\
No & 10,026 & 7.64 \\
\hline
\end{tabular}

illiterates. The likelihood of accessing health care for women from middle wealth status households was increased by $44 \%$ (AOR $=1.44 ; 95 \%$ CI: $1.54,1.79)$ compared to women from poor wealth status households whereas the odds of accessing health care women from rich wealth status households were $2030(\mathrm{AOR}=2.30$; $95 \%$ CI: $2.23,2.38$ ) times higher than women from poor wealth status households. The odds of accessing health care among women who had unwanted pregnancy were decreased by $12 \%(\mathrm{AOR}=0.88 ; 95 \%: 0.83,0.93)$ compared to women who had wanted pregnancy.

The study also revealed that the odds of accessing health care for women from Burundi, Ethiopia, Malawi, Mozambique, Tanzania, and Zimbabwe were increased by 60\% (AOR =; 95\% CI:), 55\% (AOR =; 95\% CI:), 50\% $(\mathrm{AOR}=$; 95\% CI:), 9 (AOR =; 95\% CI:,) 6\% (AOR =;

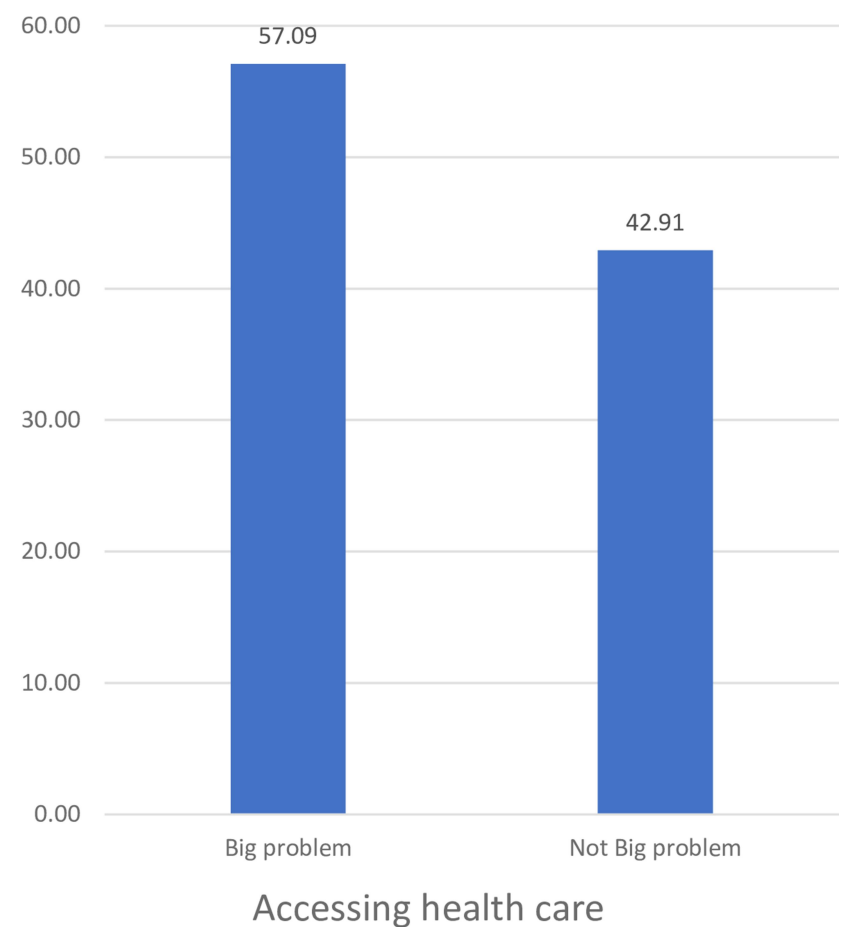

Figure 3 Overall access to health care in the East African Regions from 2008 to 2017 recent Demographic and Health Surveys.

95\% CI:,), 83\% (AOR =; 95\% CI:,), and 69\% (AOR =; 95\% CI:,) compared to women from Comoros, respectively. The odds of accessing health care for women from Kenya, Madagascar, Rwanda and Zambia were 2.75 $(\mathrm{AOR}=2.75 ; 95 \% \mathrm{CI}: 2.47,3.06), 7.62(\mathrm{AOR}=7.62 ; 95 \%$ CI: 6.87, 8.40), 2.47 (AOR $=2.47 ; 95 \%$ CI: 2.21,2.77),

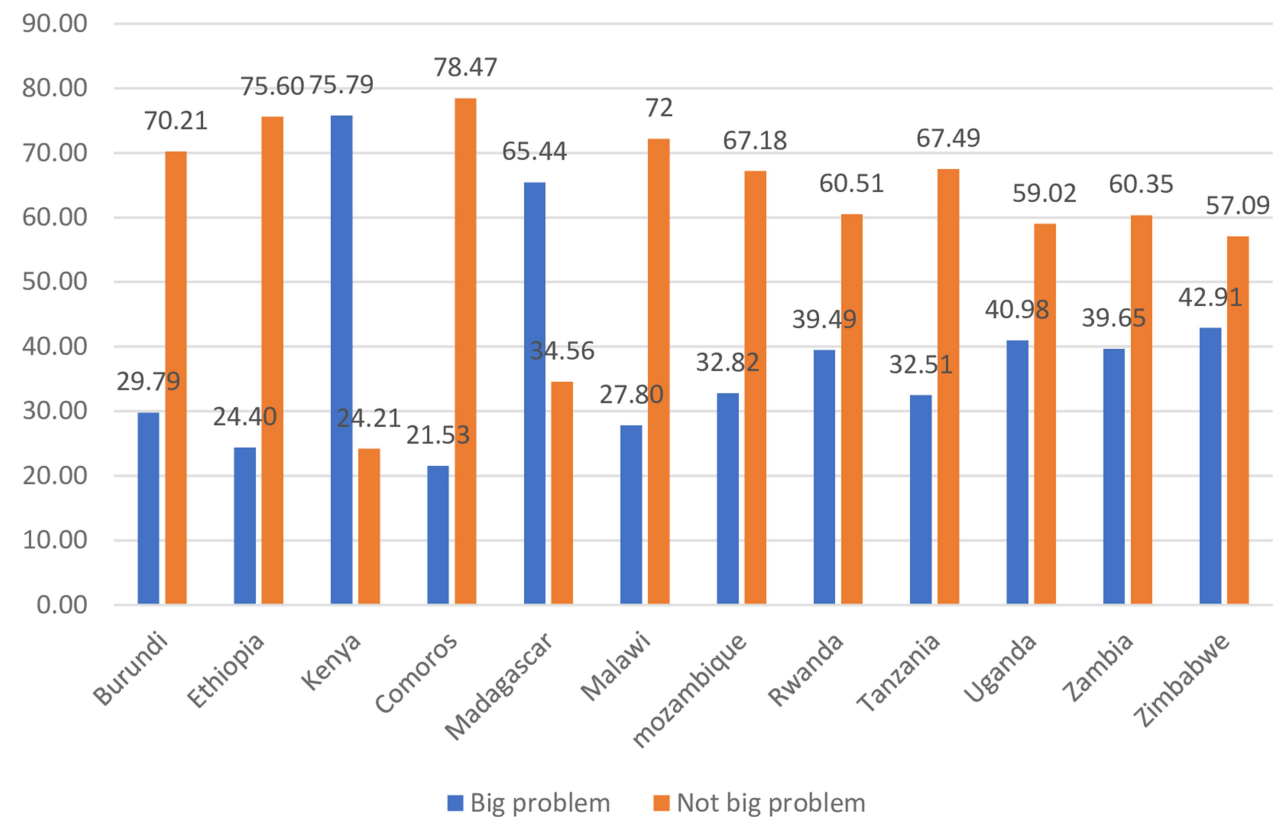

Figure 2 Access to health care in the East African Countries from 2008 to 2017. 
and $2.83(\mathrm{AOR}=2.83 ; 95 \% \mathrm{CI}: 2.53,3.16)$ times higher than women fom Comoros, respectively (Table 2).

\section{Discussion}

The finding showed that the overall coverage of women's access to health care was $57.09 \%$ in the region. The health care access coverage ranged from $75.79 \%$ in Kenya to less than $21 \%$ in Comoros. This might be due to Comoros is one of the known world's low-income economies with the insufficient transportation system, undeveloped and quickly growing population, low educational level, repeating political insecurity, now and then started from outside the country, and recurrent electricity calamity. ${ }^{27}$ The above factors may hinder women from accessing health care. On the contrary, the Kenyan's healthcare system has shown dramatic improvements by expanding health access through universal coverage has not been achieved. ${ }^{28}$ The Kenyan government has given more emphasis to the expansion of public facilities and the implementation of effective health care financing policy which increases women's access to health care in the country.

This finding is also higher than the poorest nations of the world who received at least six of seven basic maternal and child health interventions which are $17 \%$ and also lower than the wealthiest nations which are $74 \% .{ }^{29}$ The access to health care is also far from the sustainable development goal agenda 2030 in which all countries agreed to implement the initiatives in the given period. ${ }^{30,31}$ Universal health coverage (UHC) is characterized as all individuals getting quality health services that address their essential issues without being presented to financial hardship in paying for the services. ${ }^{32}$ But, the majority of women in the region who do not currently have access to care are marginalized or are in situations of vulnerability.

The study showed that residency has a significant association with women's access to health care services. Those respondents who were from rural were found to have low access compared with those who were from an urban setting. This finding is similar to other findings elsewhere. ${ }^{33-35}$ Access to health care can be affected by different factors like availability of roads, transport services, lack of health facilities, access to education, and economic limitations. Additionally, the rural population has poor access to healthcare along the dimensions of quality, proximity, and affordability contrasted with their nonfarm and urban sides. As it is known, access to information is very low, as the human anomaly is remote. For those who receive less information, it is significantly less likely that they will have access. Thus, mothers in urban areas have better access to health.

The study also showed that maternal education level and the husband's level of education were important factors in determining maternal health care access. Those women and their husbands who had primary education and above had more access to healthcare than those who could not read and write. This finding is consistent with a study done in different countries. ${ }^{36-40}$ Education is the basis for many things and hence educated people can access better sources of information and apply health education messages which they get from health institutions. It is also evident that educated women and partners benefit economically than uneducated.

The family's wealth level was a very important factor in accessing health services. The probability of accessing health care among women from middle wealth class and highest wealth class was higher compared to women with women from the lowest wealth class. This is in line with other studies conducted in different countries. ${ }^{41-45}$ Wealth is a key indicator of access to most health services, because wealthy people might be more likely to pay for what they want. Wealthier women are more likely to pay for their services and increase access to health services. It means a big impact when they are poor and cannot pay for the services.

The result also revealed that mothers who had unwanted pregnancies were less likely to access health care compared to those who had a plan to become pregnant. This suggests that women with unplanned pregnancies could have been reluctant to look for or go to ANC. Likewise, the nonappearance of a pregnancy "mindset," which is normal in sudden or undesirable pregnancy, could have applied a negative effect on mothers' utilization of health services. ${ }^{46-48}$ This is why they have better health care access than counterparts who do not have an unwanted pregnancy.

Living in different countries has been a major factor in accessing health services. Countries in East Africa vary in terms of their health system, policy, government structure, and health institutions, although many things are similar. Therefore, the difference in these cases means that there is a difference in the accessibility of women to health services. As a result, access to health services will vary.

\section{Strength and Limitation of the Study}

The dataset utilized in this finding was obtained from broadly representative 12 East Africa DHSs dataset. The 
Table 2 Multivariable Multilevel Logistic Regression Analysis of Both Individual and Community-Level Factors Associated with Accessing Health Care in East Africa Countries from 2008 to 2017

\begin{tabular}{|c|c|c|c|c|}
\hline Variables & $\begin{array}{l}\text { Null Model AOR } \\
(95 \% \mathrm{Cl})\end{array}$ & $\begin{array}{l}\text { Individual-Level Model I } \\
\text { AOR }(95 \% \mathrm{Cl})\end{array}$ & $\begin{array}{l}\text { Country-Level Model } 2 \\
\text { AOR }(95 \% \mathrm{Cl})\end{array}$ & $\begin{array}{l}\text { Full Model } 3 \text { (Individual } \\
+ \text { +Country) AOR }(95 \% \mathrm{Cl})\end{array}$ \\
\hline \multicolumn{5}{|l|}{ Residence } \\
\hline Urban & & I & & 1 \\
\hline Rural & & $0.57(0.55,059)$ & & $0.58(0.56,0.60)^{* *}$ \\
\hline \multicolumn{5}{|l|}{ Age group } \\
\hline$<20$ & & 1 & & 1 \\
\hline $20-34$ & & $0.96(0.93,1.01)$ & & $0.96(0.93,1.03)$ \\
\hline $35-49$ & & $0.96(0.91,1.01)$ & & $0.96(0.92,1.01)$ \\
\hline \multicolumn{5}{|l|}{ Marital status } \\
\hline Single & & 1 & & I \\
\hline Married & & $1.05(0.99,1.02)$ & & $1.07(0.99,1.10)$ \\
\hline \multicolumn{5}{|l|}{ Maternal education } \\
\hline No education & & 1 & & \\
\hline Primary & & $1.09(1.05,1.13)$ & & $1.06(1.01,1.10)^{*}$ \\
\hline Secondary & & $1.27(1.20,1.35)$ & & $1.22(1.15,1.29)^{*}$ \\
\hline Higher & & $1.92(1.73,2.14)$ & & $1.84(1.66,2.05)^{*}$ \\
\hline \multicolumn{5}{|l|}{ Partner education } \\
\hline No education & & I & & 1 \\
\hline Primary & & $1.10(1.06,1.14)$ & & $1.08(1.05,1.12)^{*}$ \\
\hline Secondary & & $1.29(1.23,1.31)$ & & $1.26(1.20,1.31)^{* *}$ \\
\hline Higher & & $1.69(1.57,1.82)$ & & $1.66(1.54,1.79)^{* * *}$ \\
\hline \multicolumn{5}{|l|}{ Literacy } \\
\hline Cannot read & & 1 & & I \\
\hline Can read & & $1.10(1.06,1.14)$ & & $1.12(1.08,1.16)^{*}$ \\
\hline \multicolumn{5}{|l|}{ Maternal occupation } \\
\hline Had occupation & & 1 & & 1 \\
\hline Had no occupation & & $1.03(1.00,1.06)$ & & $1.03(0.99,1.06)$ \\
\hline \multicolumn{5}{|l|}{ Wealth index } \\
\hline Poor & & I & & 1 \\
\hline Middle & & $1.43(1.38,1.48)$ & & $1.44(1.39,1.49)^{*}$ \\
\hline Rich & & $2.27(2.20,2.35)$ & & $2.30(2.23,2.38)^{* * *}$ \\
\hline \multicolumn{5}{|l|}{ Pregnancy wanted } \\
\hline Yes & & 1 & & 1 \\
\hline No & & $0.87(0.83,0.92)$ & & $0.88(0.83,0.93)^{*}$ \\
\hline \multicolumn{5}{|l|}{ Country } \\
\hline Burundi & & & $1.27(1.15,1.39)$ & $1.60(1.44,1.78)^{*}$ \\
\hline Ethiopia & & & $1.20(1.09,1.33)$ & $1.55(1.40,1.73)^{*}$ \\
\hline Kenya & & & $9.18(8.33,10.11)$ & $2.75(2.47,3.06)^{* *}$ \\
\hline Comoros & & & 1 & 1 \\
\hline Madagascar & & & $5.62(5.11,6.19)$ & $7.62(6.87,8.40)^{*}$ \\
\hline Malawi & & & $1.38(1.26,1.52)$ & $1.50(135,1.66)^{*}$ \\
\hline Mozambique & & & $1.90(1.72,2.09)$ & $1.96(1.77,2.18)^{*}$ \\
\hline Rwanda & & & $2.05(1.86,2.27)$ & $2.47(2.21,2.77)^{*}$ \\
\hline Tanzania & & & $1.54(1.39,1.70)$ & I.83 $(1.64,2.03)^{*}$ \\
\hline Uganda & & & $1.87(1.71,2.06)$ & $2.30(2.07,2.55)^{*}$ \\
\hline Zambia & & & $2.82(2.56,3.09)$ & $2.83(2.55,3.13)^{*}$ \\
\hline Zimbabwe & & & $2.37(2.09,2.56)$ & $1.69(1.51,1.93)^{*}$ \\
\hline
\end{tabular}

(Continued) 
Table 2 (Continued).

\begin{tabular}{|l|l|l|l|l|}
\hline Variables & $\begin{array}{l}\text { Null Model AOR } \\
(95 \% \mathbf{~ C l})\end{array}$ & $\begin{array}{l}\text { Individual-Level Model I } \\
\text { AOR }(95 \% \mathbf{C l})\end{array}$ & $\begin{array}{l}\text { Country-Level Model 2 } \\
\text { AOR (95\% Cl) }\end{array}$ & $\begin{array}{l}\text { Full Model 3 (Individual } \\
\text { +Country) AOR (95\% Cl) }\end{array}$ \\
\hline $\begin{array}{l}\text { Random effect } \\
\text { parameters }\end{array}$ & & & \\
ICC\% & $99 \%$ & $65 \%$ & $56 \%$ & \\
PCV\% & Referrence & 3.22 & 2.98 & $75 \%$ \\
MOR & 4.22 & & & 2.44 \\
\hline $\begin{array}{l}\text { Model comparison } \\
\text { LLR }\end{array}$ & $-90,165$ & $-70,558$ & $-90,123$ & $-70,539$ \\
Deviance & 180,330 & 141,116 & 180,246 & 141,078 \\
\hline
\end{tabular}

Notes: *Significant at P-value < 0.05, **Significant at P-value, 0.01 , ***Significant at P-value 0.001 .

Abbreviations: $\mathrm{Cl}$, confidence interval; $\mathrm{AOR}$, adjusted odds ratio; ICC, intraclass correlation coefficient; PCV, proportional change in variance; MOR, median odds ratio; and LLR, log-likelihood ratio.

study was community-based with a response rate of $>90 \%$. The information was pooled together to make a huge representative of getting to their health services detailed inside 5 years going before every country's review which ranges from 2008 to 2017 and had the option to distinguish the huge elements related with getting to health care access among the 12 East African countries to illuminate policymakers and organizers for their mediation to organize. In spite of these benefits, this investigation has the accompanying impediments. Because of the crosssectional nature of the investigation plan, the finding from this study may not build up a genuine causal relationship between the outcome variable and explanatory variables. The information was gathered based on self-report from women within five years preceding the survey and might have the probability of recall bias.

\section{Conclusion}

The level of women's access to health care was low in the region. Residence, maternal education, husband education, literacy level, wealth index, wanted pregnancy, and countries in which women live were the major determinants of accessing health care. Therefore, there should be common approaches to improve the accessibility of healthcare utilization among women in the region and financial support for the poor that enables women to use health services. Health education and promotion activities are key to increasing their knowledge about the benefits of health care services that aiming women and their partners with no education.

\section{Abbreviations}

AOR, adjusted odds ratio; CI, confidence interval; DHS, Demographic and Health Survey; ICC, intracluster correlation coefficient; MDG, Millennium Development Goal; MOR, median odds ratio; SSA, Sub-Saharan Africa; UHC, universal health coverage; WHO, World Health Organization.

\section{Data Sharing Statement}

The data is accessible on the web and you can get to it from www.measuredhs.com.

\section{Ethics Approval and Consent to Participate}

The study does not include the assortment of data from subjects. Agree to take part is not pertinent since the study is secondary information investigation dependent on DHS information.

\section{Acknowledgments}

We would like to thank the measure DHS program for providing the data set.

\section{Author Contributions}

All authors made a significant contribution to the work reported, whether that is in the conception, study design, execution, acquisition of data, analysis, and interpretation, or in all these areas; took part in drafting, revising or critically reviewing the article; gave final approval of the version to be published; have agreed on the journal to which the article has been submitted; and agree to be accountable for all aspects of the work.

\section{Funding}

No funding was acquired for this investigation. 


\section{Disclosure}

The authors announce that they have no conflicts of interest for this work.

\section{References}

1. Abedin S, Islam R, Hossain T. Antenatal care during pregnancy: a study on Naogaon district of Bangladesh. Soc Sci. 2008;3 (8):537-541.

2. Ogundipe OM, Olurinola OI, Ogundipe A. Health intervention and child health in sub-Saharan Africa: assessing the impact of the millennium development goal. J Sustain Dev. 2016;9(1):187-201.

3. Sen G, Östlin P. Gender Inequity in Health: Why It Exists and How We Can Change It. Taylor \& Francis; 2008.

4. Pega F, Veale JF. The case for the World Health Organization's Commission on Social Determinants of Health to address gender identity. Am J Public Health. 2015;105(3):e58-e62.

5. Shannon G, Jansen M, Williams K, et al. Gender equality in science, medicine, and global health: where are we at and why does it matter? Lancet. 2019;393(10171):560-569.

6. McCarthy J, Maine D. A framework for analyzing the determinants of maternal mortality. Stud Fam Plann. 1992;23(1):23-33.

7. AbouZahr C, Wardlaw T. Antenatal Care in Developing Countries: Promises, Achievements and Missed Opportunities-An Analysis of Trends, Levels and Differentials, 1990-2001. World Health Organization; 2003.

8. WHO, U., UNFPA. World Bank Group and the United Nations Population Division. Trends in Maternal Mortality: 1990 to 2015: Estimates by WHO, UNICEF. UNFPA, World Bank group and the united nations population division; 2015.

9. Organization, W.H. and UNICEF. Maternal Mortality in 2005: Estimates Developed by WHO, UNICEF, UNFPA, and the World Bank. Geneva: World Health Organization; 2007.

10. Shah IH, Say L. Maternal mortality and maternity care from 1990 to 2005: uneven but important gains. Reprod Health Matters. 2007;15 (30):17-27.

11. Kayongo M, Rubardt M, Butera J, et al. Making EmOC a realityCARE's experiences in areas of high maternal mortality in Africa. Int J Gynaecol Obstet. 2006;92(3):308-319.

12. Essendi H, Mills S, Fotso J-C. Barriers to formal emergency obstetric care services' utilization. J Urban Health. 2011;88(2):356-369.

13. Zere $\mathrm{E}$, Tumusiime $\mathrm{P}$, Walker $\mathrm{O}$, et al. Inequities in utilization of maternal health interventions in Namibia: implications for progress towards MDG 5 targets. Int J Equity Health. 2010;9(1):16.

14. Babalola S, Fatusi A. Determinants of use of maternal health services in Nigeria-looking beyond individual and household factors. $B M C$ Pregnancy Childbirth. 2009;9(1):43.

15. Baeten R, Spasova S, Vanhercke B, Coster S. Inequalities in Access to Healthcare. A Study of National Policies. European Social Policy Network (ESPN). Brussels: European Commissin; 2018.

16. Ricketts TC, Goldsmith LJ. Access in health services research: the battle of the frameworks. Nurs Outlook. 2005;53(6):274-280.

17. Schmidt-Traub G, Kroll C, Teksoz K, et al. National baselines for the sustainable development goals assessed in the SDG index and dashboards. Nat Geosci. 2017;10(8):547-555.

18. The DHS Program. Demographic and Health Surveys Methodology. Available from: https://dhsprogram.com/What-We-Do/Methodology. cfm. Accessed September 23, 2020.

19. Hogan DR, Stevens GA, Hosseinpoor AR, et al. Monitoring universal health coverage within the Sustainable Development Goals: development and baseline data for an index of essential health services. Lancet Glob Health. 2018;6(2):e152-e168.

20. Moore B, Alex-Hart B, George I. Utilization of health care services by pregnant mothers during delivery: a community based study in Nigeria. East Afr J Public Health. 2011;15:4.
21. Hadi A. An approach to reaching the poor and disadvantaged to promote health equity in rural Bangladesh; 2002.

22. Bakeera S, Wamala SP, Galea S, State A, Peterson S, Pariyo GW. Community perceptions and factors influencing utilization of health services in Uganda. Int $J$ Equity Health. 2009;8:25. doi:10.1186/ 1475-9276-8-25

23. Iyaniwura $\mathrm{C}$, Yussuf $\mathrm{Q}$. Utilization of antenatal care and delivery services in Sagamu, south western Nigeria. Afr J Reprod Health. 2009;13(3).

24. Croft TN, Marshall AMJ, Allen CK, et al. 2018. Guide to DHS Statistics. Rockville, Maryland, USA: ICF.

25. Goldstein H, Browne W, Rasbash J, et al. Partitioning variation in multilevel models. Understanding Stat. 2002;1(4):223-231.

26. Merlo J, Chaix B, Yang M, Lynch J, Råstam L. A brief conceptual tutorial on multilevel analysis in social epidemiology: linking the statistical concept of clustering to the idea of contextual phenomenon. Journal of Epidemiology \& Community Health. 2005;59(6):443-449.

27. Organization, W.H. WHO Country Cooperation Strategy at a Glance: Comoros. World Health Organization; 2016.

28. Barasa E, Rogo K, Mwaura N, et al. Kenya National Hospital Insurance Fund Reforms: implications and lessons for universal health coverage. Health Syst Reform. 2018;4(4):346-361.

29. Document, W.H.O. World Bank and WHO: Half the World Lacks Access to Essential Health Services, 100 Million Still Pushed into Extreme Poverty Because of Health Expenses; 2017:13

30. Kieny MP, Bekedam H, Dovlo D, et al. Strengthening health systems for universal health coverage and sustainable development. Bull World Health Organ. 2017;95(7):537.

31. Williams C, Hunt P. Neglecting human rights: accountability, data and sustainable development goal 3. Int J Hum Rights. 2017;21 (8):1114-1143.

32. Organization, W.H. Making Fair Choices on the Path to Universal Health Coverage: Final Report of the WHO Consultative Group on Equity and Universal Health Coverage; 2014.

33. Pappa E, Niakas D. Assessment of health care needs and utilization in a mixed public-private system: the case of the Athens area. $B M C$ Health Serv Res. 2006;6(1):146.

34. National Academies of Sciences, E. and Medicine. Health-Care Utilization as a Proxy in Disability Determination. National Academies Press; 2018.

35. Bhatt J, Bathija P. Ensuring access to quality health care in vulnerable communities. Acad Med. 2018;93(9):1271.

36. Dimbuene ZT, Amo-Adjei J, Amugsi D, et al. Women's education and utilization of maternal health services in Africa: a multi-country and socioeconomic status analysis. J Biosoc Sci. 2018;50(6):725-748.

37. Tsawe M, Susuman AS. Determinants of access to and use of maternal health care services in the Eastern Cape, South Africa: a quantitative and qualitative investigation. BMC Res Notes. 2014;7(1):723.

38. Mekonnen T, Dune T, Perz J, et al. Maternal health service utilisation of adolescent women in sub-Saharan Africa: a systematic scoping review. BMC Pregnancy Childbirth. 2019;19(1):366.

39. Karlsen S, Say L, Souza JP, et al. The relationship between maternal education and mortality among women giving birth in health care institutions: analysis of the cross sectional WHO Global Survey on Maternal and Perinatal Health. BMC Public Health. 2011;11(1):606.

40. Tey N-P, Lai S-L. Correlates of and barriers to the utilization of health services for delivery in South Asia and Sub-Saharan Africa. Sci World J. 2013;2013.

41. Namasivayam A, Osuorah DC, Syed R, et al. The role of gender inequities in women's access to reproductive health care: a population-level study of Namibia, Kenya, Nepal, and India. Int $J$ Women's Health. 2012;4:351.

42. Pons-Duran C, Lucas A, Narayan A, et al. Inequalities in sub-Saharan African women's and girls' health opportunities and outcomes: evidence from the Demographic and Health Surveys. $J$ Glob Health. 2019;9(1). 
43. Loewenson R, Nolen LB, Wamala S. Globalisation and women's health in Sub-Saharan Africa: would paying attention to women's occupational roles improve nutritional outcomes? Scand J Public Health. 2010;38(4_suppl):6-17.

44. Annan J, Donald A, Goldstein M, Martinez PG, Koolwal G. Taking Power: Women's Empowerment and Household Well-Being in SubSaharan Africa. The World Bank; 2019.

45. Fagbamigbe AF, Idemudia ES. Wealth and antenatal care utilization in Nigeria: policy implications. Health Care Women Int. 2017;38 (1):17-37.
46. Gupta S, Yamada G, Mpembeni R, et al. Factors associated with four or more antenatal care visits and its decline among pregnant women in Tanzania between 1999 and 2010. PLoS One. 2014;9(7).

47. Haddrill R, Jones GL, Mitchell CA, et al. Understanding delayed access to antenatal care: a qualitative interview study. $B M C$ Pregnancy Childbirth. 2014;14(1):207.

48. Sakeah E, Okawa S, Rexford Oduro A, et al. Determinants of attending antenatal care at least four times in rural Ghana: analysis of a cross-sectional survey. Glob Health Action. 2017;10(1):1291879.

\section{Publish your work in this journal}

Risk Management and Healthcare Policy is an international, peerreviewed, open access journal focusing on all aspects of public health, policy, and preventative measures to promote good health and improve morbidity and mortality in the population. The journal welcomes submitted papers covering original research, basic science, clinical \& epidemiological studies, reviews and evaluations, guidelines, expert opinion and commentary, case reports and extended reports. The manuscript management system is completely online and includes a very quick and fair peer-review system, which is all easy to use. Visit http://www.dovepress.com/testimonials.php to read real quotes from published authors.

Submit your manuscript here: https://www.dovepress.com/risk-management-and-healthcare-policy-journal 